\title{
Measurement of Dielectric and Thermal Properties of Leucaena Leucocephala Bio composite substrate with Different Composition Mixture
}

\author{
Azlan Aziz, Azizi Mursyidi,Rozimah Tahir and Nurul Ajleaa Abdul Rahman \\ Center of Research and Innovation (CRI) \\ Politeknik Sultan Salahuddin Abdul Aziz Shah,Persiaran Usahawan \\ Seksyen U1, Shah Alam, Malaysia.
}

\begin{abstract}
The measurements of dielectric and thermal properties for bio composite substrate conducted between the mixture of polypropylene (PP) and saw dust filler Leucaena Leucocephala $(150 \mu \mathrm{m})$. The high temperature Agilent 85070E dielectric probe and Quickline 30 Thermal properties analyser used as an instruments to measure the dielectric properties ( $\varepsilon r)$ and handling temperature of the substrate for frequency range of $1 \mathrm{GHz}$ to $20 \mathrm{GHz}$ that are suitable for radio frequency applications. The effect of increasing wood filler indicated that it will raise the DK value from 1.84 to 2.49 and decreases the thermal conductivity behaviour from 0.2 to $0.11 \mathrm{w} / \mathrm{m} . \mathrm{k}$ for all 5 mixture fabricated substrate (PP100, PB9010, PB8020, PB7030 and PB6040). In this research the composition of PP must be greater than the sawdust filler due to PP act as laminating and hold the composite structure. The result presented on this research will useful for planar antenna and microwave filter substrate up to frequency $20 \mathrm{GHz}$ and it could support the technical and vocational education tanning (TVET) learning process that hybrid the knowledge among different field.
\end{abstract}

Key words: Leucaena Leucocephala; Dielectric constant, Loss Tangent, Thermal conductivity, Bio composite

\section{INTRODUCTION}

Bio composite material that applied the wood plastic composite (WPC) method was popular lately especially for microwave frequency $(1-20 \mathrm{GHz})$ that serve as antenna substrate [1]. In microwave frequency the usage of substrate (dielectric material) for designing planar antenna was directly rely onto its dielectric constant(gr) and loss tangent(Tan $\delta$ ) value [2], while thermal conductivity value will show the properties of the material to conduct heat during the usage of wood and polymer filler [3]. The objective of the research is to provide the reading of dielectric properties and thermal conductivity value for five different mixture of Leucaena Leucocephala (LL) bio composite substrate, Table 1 below show the list of proposed composition mixture. The selection of the Leucaena Leucocephala wood filler and Polypropylene (PP) as a bonding (laminate) material for proposed substrate was due to the local availability ,cost effective, ease of machining and immune to the temperature up to 180 degree of melting point [4]. Besides that, the proposed tree will be planted in Malaysia as a commercial tree for bio refinery project [5],so it is good to exploit the opportunity to easily obtain the raw wood material for mass product later. In this research, the usage of hot and cold pressing process to fabricate the substrate rise some of the gap issue regarding the dielectric properties and heat transfer during the pressing process with Radio frequency (RF) because there is difficult to measure the temperature and their distribution inside the proposed substrate sample. It is important that, the material moisture content, humidity, pressure, venting time and pressing temperature must be closely control due to minimize the absorption of water that can create air bubble inside the sample hence, degrade the substrate usage for RF usage [6] . Previous study have reported that thermal properties of solid wood are effected by density, fiber content, structure of wood, carbon content and moisture content [7]. So the lamination of wood filler with Polypropylene will provide some resistance to 
moisture absorption and raise the immunity to the thermal conductivity. The proposed work will provide five different composition of bio composite antenna substrate, which give different variation of dielectric and thermal properties value with reflect to specific operating frequency. The variation of the dielectric properties was due to the carbon content inside of wood filler and the raise of the dielectric properties will give some information to the antenna designer the ability of their substrate to absorb or pass through the microwave signal. Previous research have found that, the higher the $\varepsilon r$ value the antenna design become more miniature and narrow in frequency bandwidth, due to capacitive effect that store more Radio Frequency (RF) energy [8].

Table 1: Five variations different compositions proposed substrate

\begin{tabular}{|c|c|}
\hline Substrate & Composition \\
\hline PP100 & $100 \%$ PP \\
\hline PB9010 & $90 \%(\mathrm{PP}), 10 \%(\mathrm{LL})$ \\
\hline PB8020 & $80 \%(\mathrm{PP}), 20 \%(\mathrm{LL})$ \\
\hline PB7030 & $70 \%(\mathrm{PP}), 30 \%(\mathrm{LL})$ \\
\hline PB6040 & $60 \%(\mathrm{PP}), 40 \%(\mathrm{LL})$ \\
\hline
\end{tabular}

\section{EXPERIMENT}

\section{Substrate Material Preparation}

Five sample was fabricated with different composition as shown in table 1 , the proposed substrate was directly fabricated with the mixture of PP and LL filler, with particle size of $150 \mu \mathrm{m}$ with no resin and chemical liquid added. The mixture of the composition is PP > LL due to the PP was act as the laminator to the wood filler. The method of hot press to melt the mixture and cold press to preserve the molecule structure was chosen because ease of fabrication method. The chosen $150 \mu \mathrm{m}$ filler was chosen due to minimize the issue of Anisotropy that can degrade the performance of substrate. The fabrication process and pressing setting were shown in figure 1 and Table 2. In order to minimize the absorption of moisture content (MC) while fabricating process the temperature was control to 250 $\mathrm{C}$ with relative humidity of $50 \%$ to $70 \%$. The pressing setting was given in Table 2 below. The venting process of each setting was set to 2 seconds to release the moisture trap inside the substrate while the pressing process conducted. Figure 2a to figure $2 \mathrm{e}$ indicate the Scanning electron microscope (SEM) for proposed substrate at $500 \mu \mathrm{m}$ magnifying.

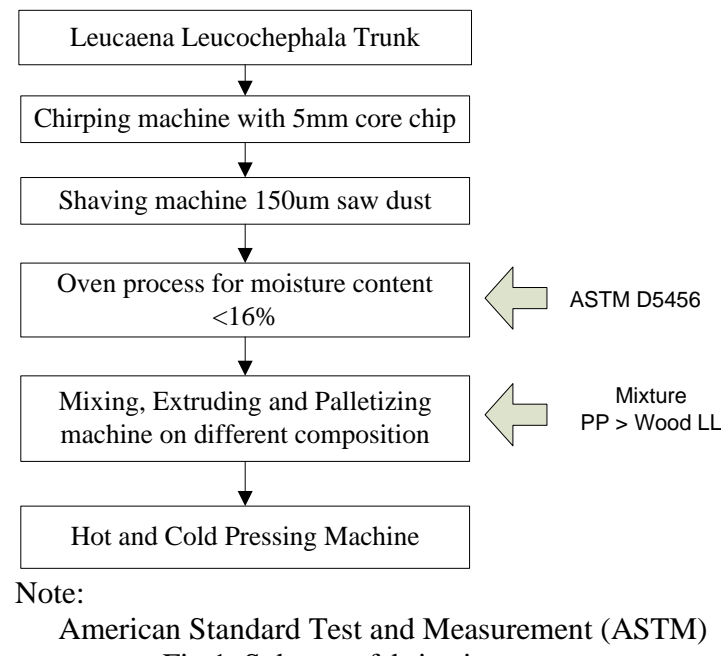

Fig 1 Substrate fabrication process

Table 2: Hot and cold press machine setting

\begin{tabular}{|l|l|}
\hline \multicolumn{1}{|c|}{ Hot Press Setting } & \multicolumn{1}{c|}{ Cold Press Setting } \\
\hline Temperature: $180^{\circ} \mathrm{C}$ & Temperature $: 20^{\circ} \mathrm{C}$ \\
\hline Pressure: $1000 \mathrm{psi}$ & Pressure: $500 \mathrm{psi}$ \\
\hline Duration: 330 seconds & Duration: 120 seconds \\
\hline \multicolumn{2}{|c|}{ Oven process $1100 \mathrm{C}$ (1 Hours) for discard } \\
moisture after final substrate fabricated (size \\
substrate $150 \times 150 \times 1.6 \mathrm{~mm}$ ) (ASTMD570-98) \\
\hline
\end{tabular}

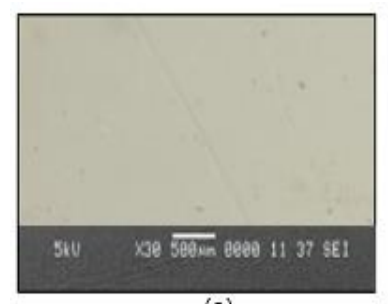

(a)

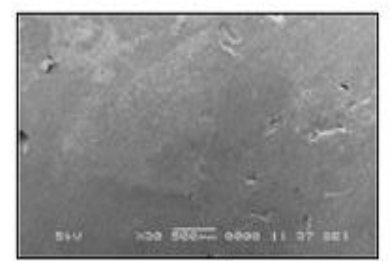

(b)

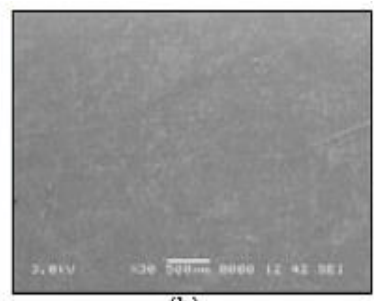

(b)

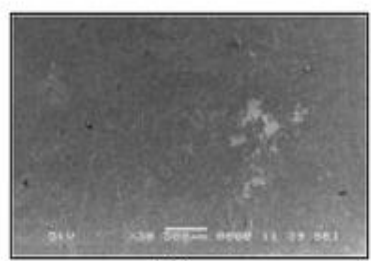

(d)

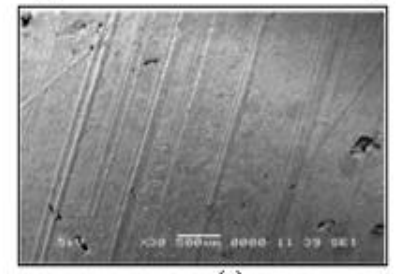

(e)

Fig 2. SEM magnifying at $500 \mu \mathrm{m}$ for proposed substrate at (a) PP100 (b) PB9010 (c) PB8020 (d) PB7030 and (e) PB6040 


\section{Dielectric Properties Measurements}

Previous research has elaborated a few technique to measure the dielectric properties of material [9].One of the most usable technique to measure the dielectric properties was high temperature probe method. The selection was based on the technique considered as nondestructive test method and it does not affect the sample performance. The probe have the capability to measure up to $50 \mathrm{GHz}$ [10], but Since the available setup for extended network analyses (ENA) capability can only measure from $300 \mathrm{KHz}$ up to $20 \mathrm{GHz}$ for the model E5071C from Agilent Technologies, the research finding was focused only for $\mathrm{L}$ Band (1 to $2 \mathrm{GHz}$ ) and up to KU Band (12 to $18 \mathrm{GHz}$ ) applications. The setup for dielectric properties measurement were indicated in figure $3 \mathrm{a}$. Since the measurement of probe method rely on reflection technique, the measurement material must be totally flat in order to reduce the multiple reflection issue that can reduce the accuracy of dielectric properties reading. In order to accomplish that, the dielectric measurement JIG were introduced in figure $3 \mathrm{~b}$, whereby the proposed substrate were placed at the middle of the measurement JIG. The JIG was fabricated with 9 different measurement hole, so that average value on each spot can be obtained to see the dielectric properties variation result. This method can also lead to verify the homogeneity of the substrate.

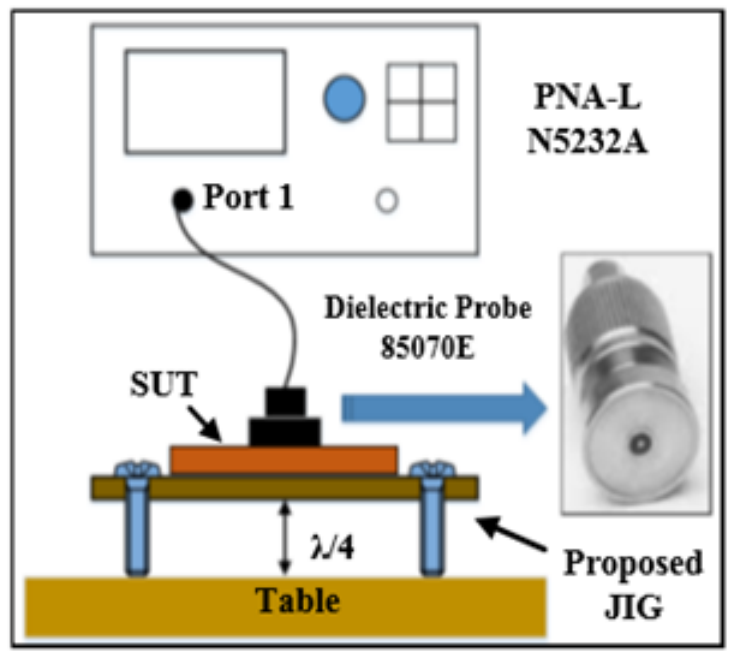

Fig $3 a$ :Dielectric probe method setup

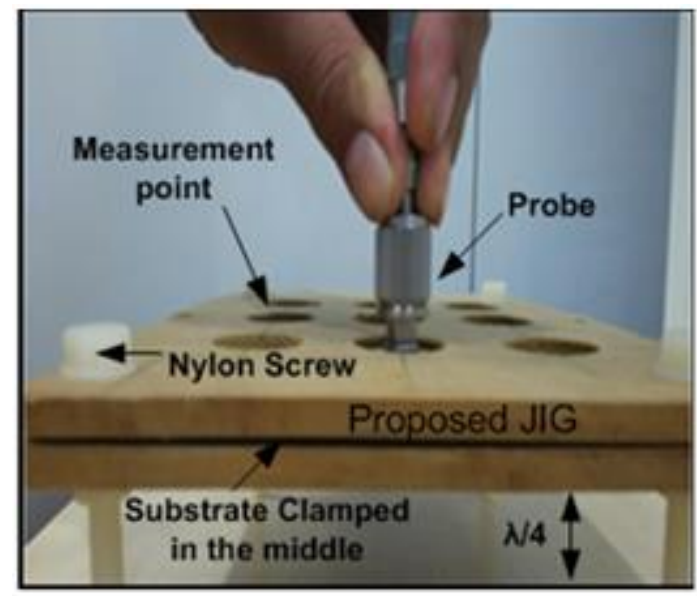

Fig $3 b$ : Measurement JIG

The measurement of dielectric properties is a combination of signal storage and loss created inside the material to perform permittivity $(\varepsilon 0)$ and permeability $(\mu 0)$ measurement. In antenna design most of the antenna designer using permittivity value, as their main design parameter. The output from ENA analyzer will give 2 main parameter, that is signal storage ( $\left.\varepsilon r^{\prime}\right)$ and material loss (er"). The permittivity value was distributed by complex number that contain real part

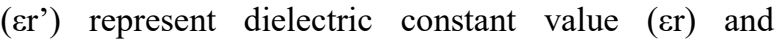
imaginary part ( $\varepsilon r$ '). So to convert the imaginary part to loss tangent (Tan $\delta$ ) value the equation (1) and equation (2) were used.

$$
\begin{gathered}
\varepsilon_{0}=\varepsilon_{\mathrm{r}}{ }^{\prime}-j \varepsilon_{\mathrm{r}}{ }^{\prime}{ }^{\prime} \\
\operatorname{Tan} \delta=\left(\varepsilon_{\mathrm{r}}{ }^{\prime} / \varepsilon_{\mathrm{r}}{ }^{\prime}\right)
\end{gathered}
$$

So dielectric constant (er) and loss tangent (Tan $\delta$ ) calculation value, will give the information to antenna fabricator to serve as primary parameter value while designing their antenna system.

\section{Thermal Properties Measurement}

Beside dielectric properties value, the thermal properties also play the important rule parameter inside substrate properties for antenna simulation software. The result of antenna design will be more precise and accurate by applying the thermal value inside thermal properties of proposed substrate. The measurement of thermal properties was conducted using Quickline ${ }^{\mathrm{TM}} 30$ Thermal properties analyzer. The measurement was focused to measure 3 main parameter, Thermal conductivity $(\lambda)$, Thermal diffusivity $(\alpha)$ and volume heat capacity (CP) with respect to the temperature ranging from $0 \mathrm{oC}$ to $40 \mathrm{oC}$ (Operating temperature range of basic device) [11]. The measurement equipment were directly display the thermal result parameter with 
specific conducting temperature $(\mathrm{T})$. The measurement were conducted by contacting the surface probe model 210411 directly to substrate material. Most of the measurement setup, were given in figure 4 , whereby material was noted as material under test (MUT).

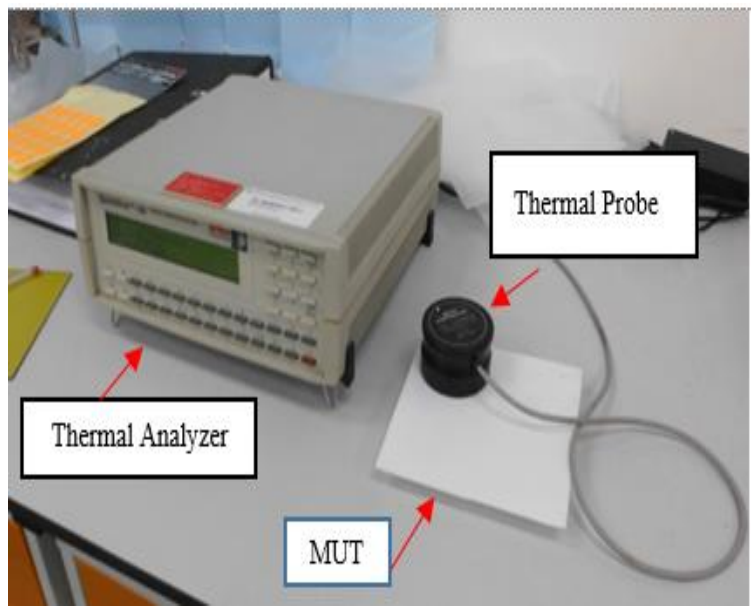

Fig 4: Thermal properties measurement setup

\section{RESULTS AND DISCUSSION}

The measurement of $\varepsilon$ r and Tan $\delta$ was measured every $200 \mathrm{MHz}$, ranging from frequency $1 \mathrm{GHz}$ to 20 $\mathrm{GHz}$. On most cases shown on figure 5a to 5e the result revealed that, the higher the mixture of wood filler will increased the average value of $\mathrm{er}$ from 1.84 to 2.49 , and decrease the Tan $\delta$ from 0.052 to 0.067 . From the dielectric graph above, even though the increment of the substrate loss directly proportional with the wood filler but the proposed substrate still considered as low loss material [12] and suitable to be used as antenna substrate with dielectric constant and loss tangent value indicated on each of the graph for proposed substrates.

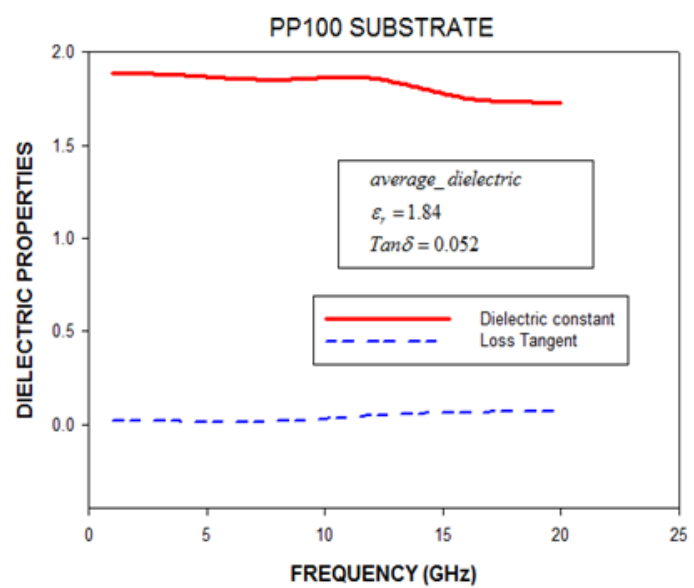

Fig 5a: Dielectric properties of PP100 Substrate

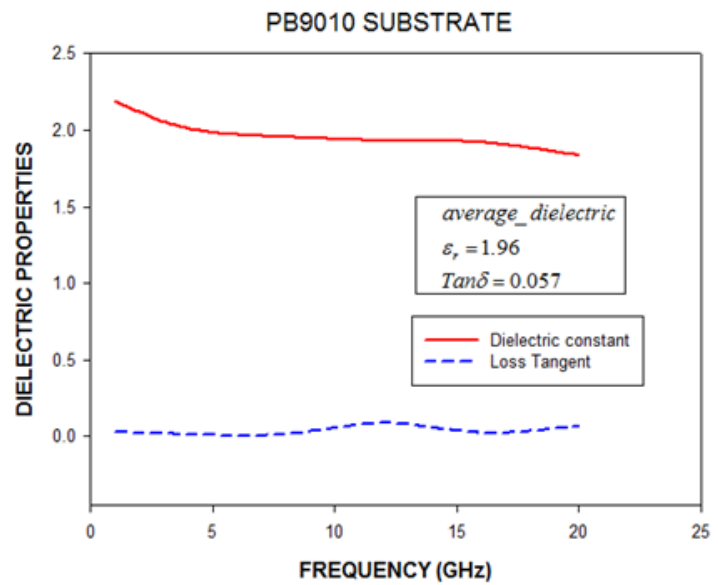

Fig 5b: Dielectric properties of PB9010 Substrate

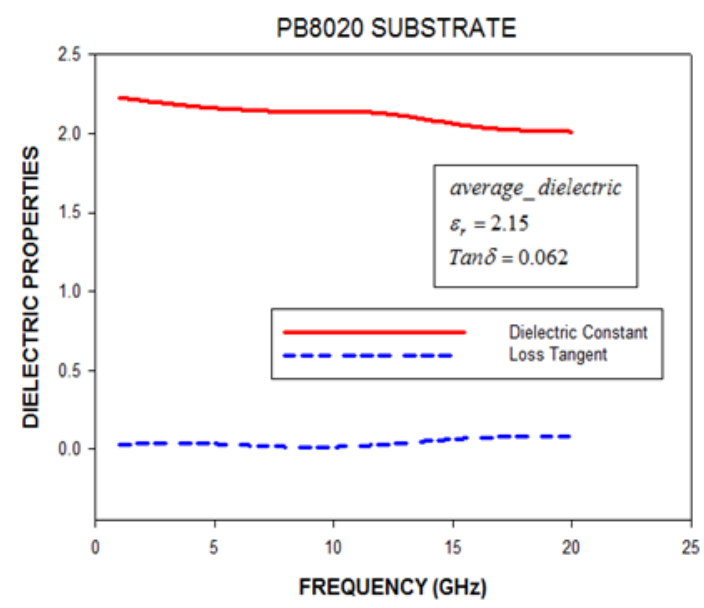

Fig 5c: Dielectric properties of PB8020 Substrate

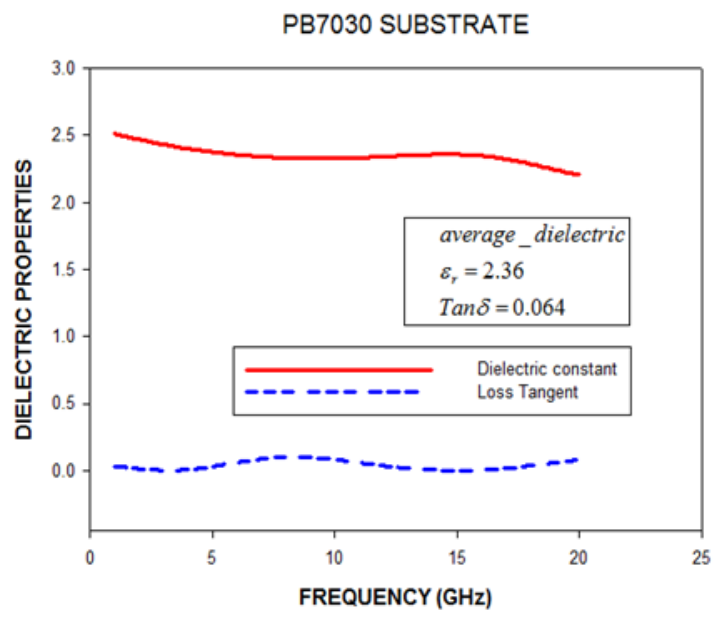

Fig 5d: Dielectric properties of PB7030 Substrate 


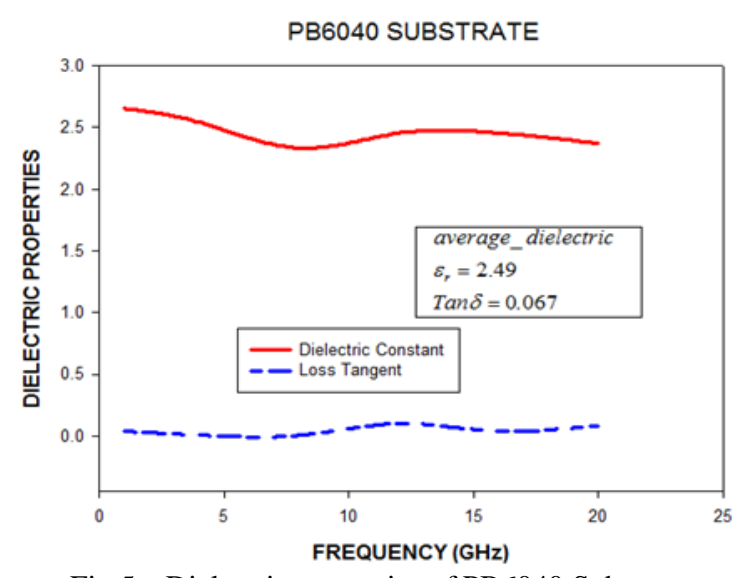

Fig 5e: Dielectric properties of PB6040 Substrate

Previous research reported that pure polypropylene material was distributed with the value of $2.2\left(\varepsilon_{\mathrm{r}}\right)$ and 0.04 (Tan $\delta$ ) measured in the surrounding of $25^{\circ} \mathrm{C}$ with frequency ranging of $1-10 \mathrm{GHz}[12]$. As referred to figure 5a, the proposed PP100 was also fabricated with pure polypropylene crystalline. On most of the time, the dielectric properties measurement was controlled at about $25^{\circ} \mathrm{C}$ with relative humidity $50 \%$ to $70 \%$, to ensure there is less MC absorption to the substrate while measurement conducted [13]. The average value of proposed PP100 substrate occurred at $1.84\left(\varepsilon_{\mathrm{r}}\right)$ and 0.052 (Tan $\delta)$. The differences between the previous and proposed substrate reported only about $0.36\left(\varepsilon_{\mathrm{r}}\right)$ and 0.012 (Tan $\delta$ ). This phenomenon is acceptable since the different material type and density of polypropylene distributed this differences. The type of polypropylene crystalline used for this experiments was fixed to Titan Pro, LOTTE CHEMICAL PD943 product for Water Quenched Blown Film (density: $0.9 \mathrm{~g} / \mathrm{cm}^{3}$ ), where the content water absorption on 24 hours is $0.02 \%$ while melting flow rate at $230^{\circ} \mathrm{C}$ is $11 \mathrm{~g} / 10 \mathrm{~min}$. The selection of this polypropylene crystalline was due to local availability in the market and the lowest value of water absorption.

The second proposed substrate named as PB9010 shown in figure $5 \mathrm{~b}$ indicated that, average of $1.96\left(\varepsilon_{\mathrm{r}}\right)$ and $0.057(\operatorname{Tan} \delta)$. This proposed substrate indicated of increment, in both dielectric properties value. The increments of $0.12\left(\varepsilon_{\mathrm{r}}\right)$ and 0.005 (Tan $\delta$ ) reported between PP100 and PB9010. The increment was due to the addition of $10 \%$ of fiber mixture and rising of the carbon content inside wood filler. As reported by [14], the carbon content can raise the value of dielectric properties, so by adding the extra wood filler that content more carbon the proposed substrate dielectric properties can raise naturally.

The proposed substrate named as PB8020, contained $80 \%$ of PP and $20 \%$ of LL wood filler. The average of $2.15\left(\varepsilon_{\mathrm{r}}\right)$ and 0.062 (Tan $\delta$ ) reported by increasing the wood filler percentage. The increment of
$10 \%$ of wood filler compared to PB9010 raise the dielectric properties value, $0.19\left(\varepsilon_{\mathrm{r}}\right)$ and 0.005 (Tan $\left.\delta\right)$. From figure $5 \mathrm{~b}$ above, by adding more wood filler to the substrate it will raise the value of loss, since more wood will increase the value of carbon and increase the intensity of signal absorption.

Beside the carbon content, MC trapped inside substrate while fabrication process can also increase the value of dielectric properties. Previous research about wood filler and PP substrate were already elaborated by [15]. In their research the substrate were directly kept and used after the process of hot and cold press without concerning about MC. In this research paper the existing process was improvised and concern about the content of MC. By referring to figure 1, the venting process and oven process was introduced to minimized the $\mathrm{MC}$ and the result by addition of this two process the dielectric properties value can be decrease from average of 3.02 $\left(\varepsilon_{\mathrm{r}}\right)$ [15] to $2.36\left(\varepsilon_{\mathrm{r}}\right)$ for composition of $70 \% \mathrm{PP}$ and $30 \%$ $\mathrm{LL}$ as indicated in figure $5 \mathrm{~d}$. The average reported for the proposed substrate named as PB7030 were averaged at $2.36\left(\varepsilon_{\mathrm{r}}\right)$ and $0.064(\operatorname{Tan} \delta)$.

The purpose of PP was act as a laminator to the wood filler, and for this research paper, no chemical additive were add to secure the whole substrate structure. So the mixture must use PP > LL, and the mixture of $60 \% \mathrm{PP}$ and $40 \%$ LL was the last substrate fabricated to form PB6040 substrate. As shown in figure 5 e the average dielectric properties reported was 2.49 $\left(\varepsilon_{\mathrm{r}}\right)$ and 0.067 (Tan $\delta$ ). The dielectric properties synchronize with previous proposed substrate (PB9010, PB8020 and PB7030) that if the mixture of wood increase the dielectric properties also increase including loss factor.

Beside dielectric properties thermal conductivity also contribute to the stability through temperature. The measurement of thermal properties for proposed substrate material have been conducted to see how the interaction of heat to the substrate stability. The result indicated in table 3 conclude that, the more percentage of wood filler the lower the thermal properties value of the substrate. The degradation of thermal conductivity value from $0.102 \mathrm{w} / \mathrm{m} . \mathrm{k}$ for PP100 to $0.091 \mathrm{w} / \mathrm{m} . \mathrm{k}$ for PB640 were reported for proposed substrate. Even though the reduction of thermal conductivity at $10.8 \%$, Thermal diffusivity at $16.1 \%$, Volume heat at $8.2 \%$ and substrate temperature conduction at $29.6 \%$ when compare the proposed substrates from PP100 to PB6040, the proposed substrate still within of the expectable value that maintained the overall thermal properties above $50 \%$ of its performance on all thermal properties value [16]. 
Table 3: Thermal properties value of proposed substrate

\begin{tabular}{|c|c|c|c|c|}
\hline Substrate & $\begin{array}{c}\text { Thermal Conductivity } \\
(\mathrm{w} / \mathrm{m} . \mathrm{k})(\lambda)\end{array}$ & $\begin{array}{c}\text { Thermal diffusivity } \\
\left(\mathrm{m}^{2} / \mathrm{s}\right)(\mathrm{a})\end{array}$ & $\begin{array}{c}\text { Volume heat } \\
\left(\mathrm{j} / \mathrm{m}^{3} \cdot \mathrm{k}\right)\left(\mathrm{C}_{\mathrm{p}}\right)\end{array}$ & $\begin{array}{c}\text { Temperature } \\
\left({ }^{\circ} \mathrm{C}\right)\end{array}$ \\
\hline PP100 & 0.102 & $0.056 \times 10^{-6}$ & $1.58 \times 10^{6}$ & 36.50 \\
\hline PB9010 & 0.100 & $0.053 \times 10^{-6}$ & $1.57 \times 10^{6}$ & 33.18 \\
\hline PB8020 & 0.098 & $0.052 \times 10^{-6}$ & $1.52 \times 10^{6}$ & 30.51 \\
\hline PB7030 & 0.097 & $0.051 \times 10^{-6}$ & $1.48 \times 10^{6}$ & 27.98 \\
\hline PB6040 & 0.091 & $0.047 \times 10^{-6}$ & $1.45 \times 10^{6}$ & 25.60 \\
\hline
\end{tabular}

\section{CONCLUSIONS}

1. Increasing the wood filler mixture for substrate from PP100, PB9010, PB8020, PB7030 and PB6040 will raise the value of dielectric constant from (1.84 to 2.49) and loss tangent (0.052 to $0.067)$.

2. The decrement of thermal conductivity value from ( 0.102 to $0.091 \mathrm{w} / \mathrm{m} . \mathrm{k})$, Thermal diffusivity $(0.056$ x10-6 to $0.047 \times 10-6 \mathrm{~m} 2 / \mathrm{s})$, Volume heat $(1.58 \times$ 106 to $1.45 \times 106 \mathrm{j} / \mathrm{m} 3 . \mathrm{k}$ ) and material conduction temperature ( 36.5 to 25.6 oC) for proposed substrate clearly stated that the different mixture of wood filler will affect the thermal properties of the substrate material. Antenna designer should take account the temperature value on each substrate so that the overall performance of their antenna substrate does not change their antenna performance due to temperature changes.

3. The improvisation of previous technique to prepare the substrate by discard the MC inside the substrate was proven to decrease $10 \%$ of dielectric constant value (introduction of venting and oven dry process).

4. Overall, the proposed PP100, PB9010, PB8020, PB7030 and PB6040 provide lower value of dielectric constant and loss tangent value suitable for 1 to $20 \mathrm{GHz}$ applications that have wide potential for printed circuit board (PCB) material, antenna substrate with a good balance between properties cost and sustainability.

\section{ACKNOWLEDGMENTS}

The authors would like to acknowledge the Malaysian Timber Industry Board (MTIB) under their subsidiary company Fiber and bio-composite development center (FIDEC) with the supervision by madam Noor Intan Saffinaz Anuar for share their facilities and equipment for the development of this article.

\section{REFERENCES}

[1]Kiew, KS, Sinin Hamdan, and MR Rahman. 2013. "Comparative Study of Dielectric Properties of Chicken Feather/Kenaf Fibre Reinforced Unsaturated Polyester Composites." BioResources 8: 1591-1603.

[2]Assis, RR, and Ildefonso Bianchi. 2012. "Analysis of Microstrip Antennas on Carbon fibre Composite Material." Journal of Microwaves, Optoelectronics and Electromagnetic Applications 11(1): 154-61.

[3]Mounika, M, and K Ramaniah. 2012. "Thermal Conductivity Characterization of Bamboo fibre Reinforced Polyester Composite." Journal material and environmental science 3(6): 1109-16.

[4]Azlan, Badrun, M.T.Ali and M.Z Awang. 2013. "A Study of Dielectric Constant and Loss Tangent of Leucaena Leucocephala Wood Plastic Composite (WPC) Substrate." IEEE Symposium on wireless Technology and Applications (ISWTA) (1): 17681.

[5]Jamin, Satiman. 2012. "Biotechnology Research Pays Off In Terengganu." New Straits Times 16/10/2012: 1 .

[6]Sahari, J, and SM Sapuan. 2012. "Effect of Water Absorption on Mechanical Properties of Sugar Palm Fibre Reinforced Sugar Palm Starch (spf/sps) Bio composites." Journal of Bio based Materials and Bioenergy 6(6): 1-5.

[7]Unsal, Oner, Umit Buyuksari, Nadir Ayrilmis, and Suleyman Korkut. 2009. "Properties Of Wood and Wood Based Materials Subjected To Thermal Treatments Under Various Conditions." In International Conference Wood Science and Engineering in the Third Millennium (ICWSE), 81-94.

[8]Nguyen, VT, and CW Jung. 2014. "Impact of Dielectric Constant on Embedded Antenna Efficiency." International Journal of Antennas and Propagation 2014(ii).

[9]Jilani, Muhammad Taha et al. 2012. "A Brief Review of Measuring Techniques for Characterization of Dielectric Materials." International Journal of Information Technology and Electrical Engineering (ITEE) 1(1). 
Azlan Aziz et al./ Journal of Engineering and Science Research, 2 (4) 2018, Pages: 20-26

[10]Engelder, David. 1990. "Dielectric materials.” In rf \&microwave measurements symposium and exhibition,

[11]Ampah, J., A. Bart-Plange, and K. A. Dzisi. 2012. Effect of

Rewetting on selected physical properties of "Asontem" cowpea variety. ARPN Journal of Engineering and Applied Sciences, (4): 389-395.

[12]Eccosorb. 2012. "Dielectric Materials Chart Eccostock." Technical Reports AFML-TR-72-39 and 74-250: 5740.

[13]Li, E, Z Nie, G Guo, and Q Zhang. 2009. "Broadband measurements of dielectric properties of Low-Loss materials at High Temperatures Using Circular Cavity Method." Progress in Electromagnetics Research 92: 103-20.
[14] Abdullah, Omed Ghareb, Gelas Mukaram Jamal, and Dana Abdull Tahir. 2011. "Dielectric Properties of Polyester Reinforced with Carbon Black Particles." In International Conference on Applied Phsics and Mathematics, 1-5.

[15]Azlan et al. 2014. "A Comparative Study of Material Leucaena Leucocephala Stem Wood Plastic Composite (WPC) Substrate with FR4 Substrate throughout Single Patch Antenna Design." Progress in Electromagnetics Research B 59(February): 151-66.

[16]Coonrod, John. 2012. "Deciphering Datasheets for High-Frequency Circuit Materials." Rogers Corporation Microwave Engineering Europe (December): 2-4. 